\title{
Distinguishing Disadvantage from III-Being in the Capability Approach
}

\section{Sebastian Östlund ${ }^{1}$}

Accepted: 31 August 2021/Published online: 22 September 2021

(c) The Author(s) 2021, corrected publication 2021

\begin{abstract}
Central capabilitarian theories of well-being focus exclusively on actual opportunities to attain states of being and doing that people have reason to value. Consequently, these theories characterise ill-being and disadvantage as deprivations of such opportunities and attainments. However, some well-being aspects are inherently negative. They make up the difference between not being well and being unwell in that they constitute ill-being. While disadvantage can be plausibly captured by deprivations, ill-being cannot be fully captured by them. I support this claim by analysing cases involving inherently negative aspects of homelessness that are not mere deprivations of opportunities to attain beings and doings that people have reason to value. I conclude that ill-being is not only about what one cannot be and do, but also about one's enduring, and opportunities to avoid, negative beings and doings. Theories and policies should reflect this to get things right, and to do right by people.
\end{abstract}

Keywords Well-being $\cdot$ Ill-being $\cdot$ Disadvantage $\cdot$ Homelessness $\cdot$ Capability approach

\section{Introduction}

When theorising about well-being, we aim to capture what makes a person's life go well for that person (Griffin 1986: 7; Sumner 1996: 20-21). Some theories assess well-being through attainments and deprivations of positive things (Alexandrova 2017: 39; Sen 1993; Yelle 2014: 369). Such positive things can be exemplified by a person's being happy, healthy, and educated. There is, however, a crucial distinction to make between living a life lacking such positive things and living a life filled with negative ones (Wall and Sobel 2020: 21).

The original online version of this article was revised. Minor typesetting mistakes have been corrected.

Sebastian Östlund

sebastian.ostlund@umu.se

1 Department of Historical, Philosophical and Religious Studies, Umeå University, Umeå, Sweden 
Negative aspects include mental states such as pain and frustration. Other examples include states of being and doing such as being assaulted, being addicted to drugs, starving, and sleeping rough. I propose that well-being theories that exclusively focus on attainments and deprivations of good things should more closely consider the many ways people's lives can go badly for them. I will argue for this claim by analysing several inherently negative aspects of homelessness.

In what follows, I use a capabilitarian framework to analyse the relevant well-being aspects. Capabilitarian well-being theories hold that what matters for people's well-being is both what reasonably valued things people could be and do, and which of these that people actually are and do. The opportunity-attainment distinction captures a crucial aspect of homelessness. Imagine that a person, Alex, is traveling across a country and lives in his vehicle while being able to secure an adequate home by, for instance, buying a house in a place he takes a liking to. Another person, Beau, may live similarly by maintaining vehicular residency while traveling the country, but is unable to secure an adequate home anywhere. Using a capabilitarian framework helps capture the difference between Alex and Beau in terms of well-being. They are differently well-off, similarly to how someone who fasts is not as badly off as someone who starves (cf. Sen (1985: 200-201; 1987a: 60-61; 1992: 52; 1993: 40)).

Alternative frameworks, such as opportunity for well-being views, can be used for similar analyses (cf. Vallentyne (2006)). However, there is a further reason for using a capabilitarian framework. Capabilitarian frameworks provide multidimensional analyses of well-being (Robeyns 2017: 56). Multidimensionality matters when considering day-to-day trade-offs that homeless people face, for instance between eating enough, resting, being warm, or being safe. Even when an option is settled on, there may be costs involved (Sen 2009: 233). A multidimensional theory of well-being that involves opportunities and attainments can show what is gained and lost in a detailed way. By attaining rest, say, the opportunity to eat is foreclosed if the person is unable to acquire money to buy food. Resting and eating both have value in terms of well-being but they cannot fully replace each other. Hence, by involving opportunities, attainments, and multidimensionality, a capabilitarian framework is well-suited for the analyses.

The capabilitarian framework has certain strengths, but there is an important and often overlooked drawback of it that my arguments will highlight and address. Analysing deprivations of good things is insufficient to capture what it means to live badly in terms of wellbeing. This is because mere deprivations or shortfalls, i.e. lacks of access to positive states or having low levels of them, obscure negative aspects. For instance, one can lack a positive state such as happiness by feeling neutral and by feeling sad. The difference between feeling neutral and feeling sad relates to the difference between not being well and being unwell. Well-being theories need to capture this distinction. This task is called 'the ill-being test' (Sumner 2020). I will show that capabilitarian well-being theories, that focus on people's attainments and deprivations of opportunities to be and do those things they have reason to value, do not currently pass it. I will then supply an addition to those theories that helps them pass the ill-being test. As a result, they will be put on par-on this point - with alternative frameworks for analysing well-being that already incorporate both positive and negative aspects in their analyses.

I will support the claim that analysing deprivations of good things is insufficient for capturing ill-being by investigating cases that involve inherently negative aspects of home- 
lessness. For instance, a person who sleeps rough is badly off but still slightly better off than a person who sleeps rough on spiked pavement. The second person suffers additional harm from policies promoting hostile architecture that are implemented to placate more well-to-do people with the political power to push certain people away from various areas. Theories that exclusively focus on shortfalls of housing will not capture the different levels of ill-being they endure well enough. Well-being theories that are formulated to not only assess but also improve people's well-being, such as capabilitarian ones, ought to track the differences between ways of being badly off. This is so that policies informed by these wellbeing theories do not end up harming people by not adequately considering effects of, and protections from, e.g. having to squat in public places (cf. Beade (2019)), and facing hostile architecture (cf. de Fine Licht (2017)).

The outline of my argument is as follows. In Sect. 2, I show that central capabilitarian well-being theories analyse disadvantage and ill-being in terms of deprivations of opportunities, beings, and doings. In Sect. 3, I argue that beings and doings beyond deprivations of good things matter in terms of ill-being. In Sect. 4, I consequently argue that capabilitarians should focus more on opportunities to avoid negative beings and doings. Section 5 concludes.

\section{Capabilitarian Disadvantage and Deprivation}

Well-being is called 'welfare', 'quality of life', 'prudential value', 'utility', and 'flourishing' in different contexts. The first three terms refer to the value of well-being without expressing commitments to any specific theory of it. The last two terms also refer to the value of wellbeing, but simultaneously express commitments to two different well-being theories. In this section, I show that utility-based theories of well-being and capabilitarian flourishing-based theories of well-being handle ill-being in importantly different ways.

Utility-based well-being theories hold that improving a person's well-being requires that the person has a favourable attitude in relation to something (Sumner 1996: 38-39). Such favourable attitudes can consist in happiness, pleasure, or desire-satisfaction (Alexandrova 2012: 680-681; Angner 2010: 364-365; Heathwood 2020: 1; Sen 1987b: 12). Similarly, according to utility-based well-being theories, unfavourable attitudes such as pain, suffering, or desire-frustration make lives go badly in terms of well-being (Kagan 2014: 268-272; Kahneman and Krueger 2006: 4-5; Sumner 1996: 131, 143, 148). Utility-based well-being theories thus focus on both good and bad experiences. These experiences are captured by these favourable and unfavourable types of attitudes.

In contrast to utility-based well-being theories, flourishing-based well-being theories do not require the involvement of any attitudes (Griffin 1986: 53). Instead, flourishing-based well-being theories often focus on essential human features and meeting needs relating to human nature (Hurka 1993: 9-18, 37). This focus on essential human features and needs creates a focus on attainments of positive states. This is because essential features cannot be realised to negative degrees (Hurka 1993: 100-101; Sumner 2020: 429-430). To see why, imagine that humans are essentially rational. On flourishing-based theories of well-being, a person may be more or less rational, but a complete lack of rationality is the limit for how bad it can get. According to those theories, there is nothing beyond such zero-points to consider. 
Capabilitarians focus on attainments and deprivations of people's actual opportunities to be and do the things that they have reason to value (Byskov 2020; Crocker 2008: 269-270; Khader and Kosko 2019: 186). These actual opportunities are called 'capabilities'. A person, $\mathrm{P}$, has a capability to hydrate, for instance, when $\mathrm{P}$ satisfies external conditions such as having access to potable water, and satisfies internal conditions such as having a healthy kidney, that jointly facilitate hydration. Once such an opportunity is realised by $\mathrm{P}$, then $\mathrm{P}$ attains what's called a 'functioning'.

Sen (1980) focuses on capabilities to meet basic needs when proposing the capability approach as an alternative to utility-based theories of well-being. A basic need is something that must be met for a person to flourish. Examples include having enough to eat, and having safe shelter (Noddings 2002: 446). Meeting basic needs is vital to living well and identifying these needs is an important step when formulating a capabilitarian theory of well-being.

A plurality of capabilitarian well-being dimensions is discussed in the literature. Here, 'a well-being dimension' should be understood as 'a functioning-capability pair'. Nussbaum (2000: 78-80; 2003: 41-42; 2011a: 33-34) provides a list of capabilities based on purportedly essential features of human flourishing. She argues that these ten central human capabilities are distinct in kind, and that a fully flourishing life needs to meet some threshold level for each item on the list. They are, on Nussbaum's (2011b: 23) view, entitlements that are "inherent in the idea of basic social justice". Because essential human features, rather than subjective attitudes, grounds Nussbaum's list of central capabilities, it is sometimes called an 'objective list' (cf. Parfit (1984: 4) and Rice (2019: 1074)). The more items on this objective list that a person has access to and the greater degree to which each item can be fulfilled by that person, the higher that person's well-being is said to be. Conversely, the fewer items on this objective list that a person can attain, and the lower the degree is to which each item can be attained by that person, the lower that person's well-being is said to be.

Some plurality of well-being dimensions in the capability approach is generally accepted by capabilitarians. However, different capabilitarians focus on different dimensions. Unlike Nussbaum, Sen (1993: 46-48; 2004a; 2005: 157-160) is reluctant to settle on a list of central capabilities and functionings without involving public participation. Nevertheless, Sen gives direction for the public's decisions concerning what to put on its list. Sen (1987b: 8) offers examples such as people's mobility, ability to satisfy their nutritional needs, and their opportunities for being decently dressed and being active members of their community. Other examples involve states such as having sufficient status, self-respect, and opportunities to appear in public without shame (cf. Sen (1993: 31-35; 1999: 71; 2005: 154)). The well-being dimensions that Sen captures with his examples are all such that we have reason to value them. Sen (2004b: 5) argues that "functionings are constitutive of a person's being, and an evaluation of a person's well-being has to take the form of an assessment of these constituent elements". The examples that Sen provides help motivate the capability approach and guide the public's list-making.

The commitment to focusing on capabilities and/or functionings that we have reason to value comes out clearly in a Senian method for ranking capability sets (Sen 1987b: 43-44). A capability set is a collection of actual opportunities to realise beings and doings that a person has reason to value. Here, the notion of set dominance is relevant for understanding how the 'reason to value'-qualifier affects how well-being dimensions should be assessed. It can be understood as follows. First, count education as a well-being dimension. Next, 
consider a brother that can be and do everything that his sister can, but is the only one of them who can be educated. Since the brother has one more capability and/or functioning, the brother's capability set dominates the sister's. He is consequently better off in terms of well-being than the sister is.

Implementing the method of set dominance to assess levels of well-being indicates that each capability and functioning is positive to some extent (Sen 1992: 42-46). Sen (1992: 46) puts it, "[h] aving more of each relevant functioning or capability is a clear improvement". This means that capabilities and functionings matter when assessing a person's wellbeing if and only if having the capabilities and functionings improves a person's well-being.

Consequently, if adding one more capability or functioning could make a person not be better off in terms of well-being, then that capability or functioning is irrelevant to assessing well-being because it is non-positive. Capabilities or functionings could be non-positive either by being neutral (e.g. picking between functionally equivalent toothpastes) or negative (e.g. enduring pain). Such non-positive capabilities and functionings are excluded due to the focus on purportedly essential features of human flourishing in the case of Nussbaum, and in the case of Sen due to his examples combined with rankings through set dominance.

Sen's and Nussbaum's well-being theories maintain that attaining capabilities and functionings makes a person's well-being increase, and not attaining them makes a person's well-being decrease. On these theories of well-being, severely low well-being, i.e. ill-being, is therefore analysed as deprivations of beings and doings that we have reason to value.

Notably, a capabilitarian hallmark work on disadvantage also subscribes to this view of faring ill exclusively through deprivation. Wolff and de-Shalit (2007: 9) define 'disadvantage' as "a lack of genuine opportunity for secure functioning" (my emphasis), where 'functioning' in turn is defined as "[t]hese 'beings and doings' that one has a reason to be or do" (2007: 37). This view of faring ill captures something important, just as related capabilitarian indices such as the Human Poverty Index and Global Multidimensional Poverty Index that measure functioning deprivations do (OPHI and UNDP, 2020: 4-5; UNDP 2010: 94-95; 2018: 9). However, despite the importance of these capabilitarian theories and applications, in the next section I show that being deprived of positive beings and doings is only one way of faring badly in terms of well-being. Based on this finding, I will subsequently argue that capabilitarian theories and applications should expand their focus to appropriately capture inherent ill-being aspects.

\section{III-Being Beyond Capability Deprivation}

In this section, I identify differences between deprivations of positive well-being dimensions and realisations of negative well-being aspects. The differences are illustrated by comparisons of beings and doings that deprived people instantiate, but whose well-being badness goes beyond mere deprivations. In subsection 3.1, I present what Sumner (2020) calls 'the ill-being test'. According to this test, well-being theories ought to adequately capture inherently negative well-being aspects. In subsection 3.2, I present cases involving inherently negative well-being aspects that go beyond being mere deprivations of positive opportunities, beings, and doings. I conclude that capabilitarian well-being theories need to be modified to pass the ill-being test. 


\subsection{The III-Being Test and the No-Basic-Bads View}

The ill-being test formulated by Sumner (2020: 421-430) states that a well-being theory must account for substantive bads (or 'basic bads', cf. Rice (2019)). The reason they should be accounted for is that they explain how a being or doing can shift from not being worth having, to being worth not having (cf. Kagan (2014: 261-262)).

For the sake of argument, I accept Rice's (2019: 1076-1084) view that for some dimensions, the absence of good and the presence of bad are equally bad. For example, it could be correct that when we compare three individuals, A, B, and C, where (1) A has knowledge of X, B has no knowledge of X, and C has false beliefs about X; (2) A has healthy relationships, $\mathrm{B}$ has no healthy relationships, and $\mathrm{C}$ has only unhealthy relationships; and (3) A has success in projects, $\mathrm{B}$ has no started projects, and $\mathrm{C}$ only failed projects, then $\mathrm{A}$ is best off in each case, but B and $\mathrm{C}$ are equally well-off. However, this symmetry between $\mathrm{B}$ and $\mathrm{C}$ does not generalise to all cases.

Rice's position is moderate in the sense that it does not go beyond a claim about beliefs, relationships, and projects. There is, however, a radical generalised version of Rice's position that would undermine my argument if it were true. The radical generalised version states that it is true for all well-being dimensions that the absence of good is equally as bad as the presence of bad is. If this stronger claim is true, then people can fall differently far away from attaining positive capabilities and functionings but cannot endure negative well-being aspects since (purportedly) none exist. We may call it 'the no-basic-bads view'. Capabilitarian well-being theories implicitly affirm this view when analysing ill-being as deprivation of positive capabilities and/or functionings.

In the upcoming comparisons, different scenarios of people like Rice's person C are analysed. In these comparisons, we can note that there are always relevant differences between $\mathrm{C}$ vis-à-vis people like $\mathrm{A}$ and $\mathrm{B}$, and sometimes between different versions of $\mathrm{C}$.

If unfavourable attitudes are not considered in a utility-based assessment of how well people are doing, the assessment would give a distorted view of people's well-being. To see why, consider a crude questionnaire about the number of hours that people have felt happiness the previous week. Imagine that a person, Charlie, indicates ' 20 ' as the number of hours he has been happy two weeks in a row. Charlie could be assessed as doing equally well during both weeks if duration of happiness were all that mattered. Next, imagine that Charlie felt $5 \mathrm{~h}$ of pain during the first week, but felt $10 \mathrm{~h}$ of (a corresponding level of pain the second week. This difference in levels of well-being during the two weeks is lost on the crude questionnaire.

If more than deprivations of positive opportunities, beings, and doings matter for people's well-being, contrary to the no-basic-bads view, then capabilitarian well-being theories should be complemented with an additional claim. The additional claim states that living badly involves enduring negative beings and doings. It should be considered alongside the claim that living badly involves failures to attain positive beings and doings. The importance of this addition can be gauged by looking at cases involving expressions of homelessness. In these cases, deprivations only capture positive states that similarly situated people fail to attain. By contrast, a focus on ill-being captures differences regarding negative states that people endure and whether they can avoid enduring them. For instance, someone who does not attain much happiness but at least does not endure any pain is better off than someone who similarly does not attain much happiness but, by contrast, endures some pain. In terms 
of these well-being aspects, the first person's situation could be improved exclusively by increasing his or her amount of happiness. The second person's situation could be improved by increasing his or her amount of happiness and by having him or her alleviate or avoid the pain. In what follows, I will show that there are several similarly relevant well-being aspects to consider.

\subsection{Homelessness and III-Being Beyond Deprivation}

Living badly involves aspects beyond deprivations of positive well-being dimensions. To see why, imagine a homeless person, Drew, who is acutely anxious while running away from some thugs. The thugs are trying to steal Drew's backpack which contains all her belongings. Moreover, after recently having met a caseworker who told Drew that there are no available spots in the local shelter for the foreseeable future, she is simultaneously enduring long-term stress about surviving the winter. Drew is thus decidedly deprived of positive states such as calmness.

If we only consider Drew as being deprived in the case with the thugs, we will overlook important differences between her negative well-being aspects. We can imagine that Drew is made calmer by ingesting medication that removes injurious aspects of anxiety but that nevertheless leaves her agitated in the long-term stress sense. Acute anxiety and long-term stress can both loosely be considered deprivations of calmness or, say, mental health. However, their qualitative differences should be captured whichever positive wellbeing dimension we consider Drew to fall short of. If a well-being theory misses differently negative qualities, and informs policies geared to promote people's lives, then the policies will run the risk of missing them, too. To address the long-term stress, social support from a caseworker might be sufficient to bring relief (cf. Durbin et al. (2019: 1059)), while the medication might only address the anxiety. Policies that focus exclusively on attaining positive states can fail to remedy inherent ill-being aspects. This does a disservice to the people that the policies should be helping.

We might try to understand the case of anxious and stressed Drew through the notion of a covering value. A covering value is, following Chang (1997: 5), "any consideration with respect to which a meaningful evaluative comparison can be made". Value relations such as $\mathrm{X}$ being better than $\mathrm{Y}, \mathrm{X}$ being as valuable as $\mathrm{Y}$, and $\mathrm{X}$ being worse than $\mathrm{Y}$, rely on a covering value for the comparisons (Chang 1997: 5-6). However, calmness, mental health, tranquillity, serenity, and similarly positive variants are inadequate as covering values here. They do not provide meaningful comparisons between the different aspects of acute anxiety and long-term stress. Both acute anxiety and long-term stress undermine the realisation of the listed positive states. However, their presences are inherently negative in a similar way to how pain is negative on some utility-based theories of well-being. Moreover, they are differently negative similarly to how social status and eating enough are positive but dissimilar dimensions in some capabilitarian well-being theories. This makes it difficult to say whether someone without acute anxiety is more calm, as calm, or less calm than someone without long-term stress, for instance.

It is difficult to always identify a covering value that covers a spectrum between some positive extreme such as calmness and one privileged negative extreme-what Kagan (2014: 273) calls an "opposite" or "partner" to the positive state. Instead, we should allow for several spectra between e.g. calmness and different inherently negative states. Simply 
saying that someone is deprived of calmness does not help us ascertain which of the negative extremes are present in her life. Both anxiety and stress are negative extremes that Drew endures. We need more information about Drew's ill-being than noting a deprivation of some positive state offers. Thus, the distinctness of inherently negative beings and doings should be acknowledged.

A proponent of the no-basic-bads view might object by claiming that the differences between anxiety and stress are captured by different deprivations rather than distinct negative states. What really goes on, the objector insists, is that Drew lacks two types of calmness, say, calmness ${ }^{\mathrm{a}}$ and calmness ${ }^{\mathrm{b}}$. Acute anxiety undermines calmness ${ }^{\mathrm{a}}$ and long-term stress undermines calmness ${ }^{\mathrm{b}}$. It might be said, in line with Wolff and de-Shalit (2013: 161), that homelessness has been a corrosive disadvantage. A corrosive disadvantage creates several, compounded, deprivations (Wolff 2009: 221). Consequently, by specifying detailed deprivations of different well-being dimensions, the objector holds that we can avoid positing negative beings and doings.

In response, I submit that the more fine-grained positive well-being dimensions rely on descriptions of negative states. When identifying ill-being, e.g. to help people in bad conditions, we should capture, and address, those things that poorly off people endure. Anyone who has experienced hunger pangs can tell you what feels bad about them. Even if not feeling full can be captured as a shortfall of satiation, it is neutral with regard to satiation in a way that feeling hunger pangs is not. There is a distinctly negative experience that can be isolated for hunger pangs. Positing more fine-grained positive well-being dimensions than satiation to identify the difference will not do the required work. Similarly, it is not plausible that psychological conditions such as anxiety are mere deprivations of some positive state(s). After all, anxiety is clinically diagnosed in part by noting the presence of negative states (American Psychiatric Association 2013: 189-233). Hence, even if my claims about Drew's anxiety could be translated into the absence of things like calmness ${ }^{\mathrm{a}}$, descriptions of things like calmness ${ }^{\mathrm{a}}$ need to be about absences of negative states so that the intended phenomenon, i.e. anxiety, will be captured. An absence of calmness ${ }^{\mathrm{a}}$ would entail an absence of absence of negative states which is equivalent to some of them being present. Consequently, inherent ill-being aspects can reappear even after proponents of the no-basic-bads view attempt to translate them into deprivations.

There are inherent ill-being aspects of homelessness that go beyond sensations of anxiety and stress. Consider, for instance, that homelessness often involves social exclusion in Western societies (van Zalk and Smith 2019: 2). To see what this entails, consider the following hypothetical case about social standing. Imagine a homeless person, Elliot, who panhandles on a street corner in a wealthy Western nation. Waves of busy people pass Elliot as they walk to work. Human recognition is unattainable as he is practically invisible to them. Hence, Elliot is ignored and ostracised. Next, consider another homeless person, Freddie, who tries to find a protected place to sleep in a city centre of the same wealthy Western nation. Suddenly, police officers show up by Freddie's makeshift bed and tell her to leave, as they find her presence disturbing. Freddie, correctly believing issues will increase if the police officers' demand is not met, settles down in a less central place. Freddie is thereby demeaned and dominated.

There are important well-being differences between Elliot and Freddie that are not captured by noting that they are both deprived of social standing. It is not a difference in terms of magnitude of something valuable, i.e. that they are deprived of social inclusion to differ- 
ent extents, that is at stake for Elliot and Freddie. The life experiences of Elliot and Freddie could well be had by the same person, for which the issues are then compounded in a different way to how e.g. adding an hour's worth of intense pain to another hour's worth of some other level of pain compounds. Elliot and Freddie have a lower social standing than housed people do. In that sense, they both suffer from a disadvantage in comparison to housed people. However, the relevant comparisons between Elliot and Freddie do not stop at this disadvantage. Interventions educating the public about the dignity of homeless people granted to them as fellow humans might help when people do not see them as fully human (cf. Johnstone et al. (2015: 2)). This could mitigate the ostracism Elliot endures. However, interventions that relax the police's attitude toward homeless people would be needed, too, to remove the domination that Freddie faces. Ostracism and domination may both underlie failures to achieve social standing, but are substantially different life experiences that are inherently negative in terms of well-being.

Another hypothetical case involving inherent ill-being concerns access to shelter. Imagine that a homeless person, Gail, sleeps rough on the streets of Skid Row. He is thereby deprived of something positive like living standards involving a warm, dry, and clean bed (etc.). There is, as Batterham (2019: 280) points out, a capability deprivation or a forced lack for homeless people such as Gail. However, beyond this deprivation, there are other relevant well-being aspects to consider that become apparent when the case is fully fleshed out. While Gail has access to nearby social services on Skid Row, the risk of assault is high when sleeping outdoors in such a populated area (cf. Heslin et al. (2007: 203-204)). Gail therefore becomes fearful. Sleeping rough like this also decreases privacy, e.g. by having to perform bodily functions in public (Kohn 2004: 130-132). Gail's way of lacking shelter thus involves humiliation as well. Both his fearfulness and humiliation are more than mere deprivations of positive well-being dimensions involving comfort, safety, and respectful recognition.

In summary, central capabilitarian well-being theories focus on people's flourishing through their opportunities, beings, and doings. However, the ways in which people such as Drew lack calmness, or Elliot and Freddie lack social standing, or people such as Gail lack shelter, encompass different conditions that they must endure, not just conditions that they miss out on. The following table 1 provides an overview of the relevant well-being aspects.

Drew is deprived of calmness, but that is not the end of it. Drew cannot avoid suffering from long-term stress. Elliot is deprived of social standing. Moreover, Elliot cannot avoid being ignored and ostracized. Similarly, Freddie is deprived of social standing. But, importantly, it is also the case that Freddie cannot avoid being demeaned and dominated.

Table 1 A summary of the exemplified homeless people's described capability and functioning attainments, deprivations, and inherent ill-being

\begin{tabular}{llll}
\hline Name & $\begin{array}{l}\text { Capability/Functioning } \\
\text { Attainment }\end{array}$ & Deprivation & $\begin{array}{l}\text { Presence of Negative } \\
\text { Being/Doing }\end{array}$ \\
\hline Drew & Can medicate her anxiety & Lacks calmness & $\begin{array}{l}\text { Is acutely anxious and } \\
\text { has long-term stress } \\
\text { Elliot }\end{array}$ \\
Freddie & $\begin{array}{l}\text { Can seek resources to meet basic needs } \\
\text { ramifications }\end{array}$ & $\begin{array}{l}\text { Lacks social } \\
\text { standing }\end{array}$ & $\begin{array}{l}\text { Is ignored and } \\
\text { ostracised }\end{array}$ \\
Gail & Can find social service locations nearby & Lacks social & $\begin{array}{l}\text { Is demeaned and } \\
\text { dominated }\end{array}$ \\
\hline
\end{tabular}


One of the central signs of homelessness is to lack lodging, which Gail does. Moreover, the way in which Gail lacks lodging, he cannot avoid being fearful and humiliated. They are all deprived of various good things, which something like a disadvantage view can capture. But that is not the end of their plights. Even if having false beliefs, unhealthy relationships, and failed projects, is not negative in terms of well-being, as Rice (2019) argues, there are several other beings and doings that are plausibly inherently negative, i.e. basic bads. Capabilitarians about well-being should therefore acknowledge that besides there being many ways to flourish and fall short of so doing, there are ways to suffer from ill-being beyond being deprived. By importing utility-based theories' concern with basic bads, capabilitarians can improve their theories of well-being. To capture such basic bads, capabilitarian well-being theories will need a foundational modification.

\section{Negative States and Harm Reduction}

The cases in Sect. 3 show that homelessness can be expressed in various ways. In light of these cases, we see that homelessness involves experiences from three well-being categories: (1) capability and/or functioning attainment, (2) deprivations, i.e. lacks of capability and/or functioning attainment, and (3) the presence of negative beings and doings and lack of control over them in a person's everyday life, given the circumstances he or she is in. Only the first two categories are properly captured by the central capabilitarian well-being theories. As a result, the central capabilitarian well-being theories cannot currently make enough sense of the distinction between states not being worth having and states worth not having.

To help capabilitarian well-being theories pass the ill-being test, I recommend the following foundational modification. Capabilitarian well-being theories ought to list states of being and doing that people are better off to the extent that they are free not to attain and actually do not attain. The classical way of defining 'capabilities' is by the expression 'actual opportunities to be and do the things that people have reason to value'. By contrast, the expanded focus on states that we have reason to disvalue additionally involves opportunities to avoid prudentially negative beings and doings. By combining these viewpoints, a person's well-being is thereby assessed (1) in terms of his or her attained valuable beings and doings, (2) his or her actual opportunities for attaining valuable beings and doings, (3) his or her attained disvaluable beings and doings, and (4) his or her actual opportunities for avoiding disvaluable beings and doings. The classical definition restricts capabilitarian analyses to the first two aspects and analyses them in terms of positive capabilities and functionings. But by acknowledging the existence of beings and doings that are basic bads, the latter two aspects can be properly accommodated also within capabilitarian well-being theories.

The foundational modification that I propose expands the scope of beings and doings that capabilitarian well-being theories should cover. Since those beings and doings are negative rather than positive, the modification brings capabilitarian well-being theories closer to other well-being theories that already analyse inherent ill-being aspects such as pain and consequently pass the ill-being test (cf. Bradford (2021: 589)). A comparative strength of the modified capabilitarian well-being theories, however, lies in being able to differentiate levels of well-being for a person who tries sleeping rough one night to see what it's like, and a person who cannot avoid sleeping rough. The two are differently badly off that 
night, even when all other circumstances are fixed. The suitably modified capabilitarian well-being theories can explain why. The first person is free to avoid enduring the negative aspects, whereas the latter one is not. The modification does not simply focus on people's beings and doings, but also their actual opportunities for avoiding negative ones. Thus, the modification retains the capabilitarian two-fold focus on what people actually are and do, and what people can be and do.

A consequence of adopting my foundational modification to capabilitarian well-being theories is that ranking methods involving set dominance, and lists consisting only of positive dimensions, need to be complemented. By way of example, a person who avoids being stressed, anxious, ostracised, dominated, fearful, and humiliated does better than someone who does not. Similarly, a person who has an actual opportunity to avoid being any of these negative things will be better off than someone who cannot, ceteris paribus, even if they both endure them. This helps us distinguish people who try to see what it's like to experience negative beings and doings from those who cannot avoid facing those beings and doings. Both the bad things, and opportunities for avoiding them should be included in our overall assessments. Thus, two tasks follow.

First, regarding set dominance, the presence of the same valuable capabilities and functionings for two people does not necessarily entail that they are equally well-off. This is because negative beings and doings have not been considered. Hence, the ranking method can be retained only by including actual opportunities to avoid negative states of being and doing, alongside avoidances of negative beings and doings. Fortunately, this largely amounts to taking in more information about various opportunities, beings, and doings. Thus, the foundational modification lets set dominance ranking methods function similarly, even if it requires them to include more information than the positive capabilities and functionings provide.

Second, the foundational modification reveals a need for complementing flourishingbased capabilitarian theories of well-being. These well-being theories need to better encompass ways in which life is not just going not well, but actively going badly in terms of the beings and doings people face as well as their (lack of) control over them. However, since essential human features cannot be realised to negative degrees, this poses a challenge to capabilitarians who wish to ground the relevant opportunities and states in a unified account. Either the negative beings and doings ought to be grounded in some separate substantial theory of prudential badness, or they ought to be identified as relevant on a case-by-case basis. Whichever alternative is opted for, something beyond essential human features needs to be appealed to.

It may be objected that my proposed foundational modification is unnecessary for identifying what makes people's lives go badly. For instance, Wolff and de-Shalit's theory of disadvantage inherits the no-basic-bads view that is implicit in Sen's and Nussbaum's capability theories of well-being. This inheritance is arguably to be expected since Wolff and de-Shalit (2007: 38) use Nussbaum's list of ten central human capabilities as a starting point for their own theory. On their view, deprivations of those well-being dimensions will lead to disadvantage (Wolff and de-Shalit 2007: 40). Beyond such deprivations, Wolff and de-Shalit (2007: 94) also include the risk of losing valuable functionings as a part of being disadvantaged. Thus, people are disadvantaged to the extent that they do not attain the relevant well-being dimensions, or when functionings are insecure in the sense that people may easily lose them (Wolff and de-Shalit 2007: 68). On this view, it makes sense to say 
that a person who tries sleeping rough has greater functioning security than a person who cannot avoid sleeping rough.

Capabilitarian well-being theories should, despite the objection described above, be modified to capture negative beings and doings, and not just focus on security of valuable functionings. They should do so because reducing harm is sometimes possible even when reducing functioning deprivation is not. It is possible to alleviate inherent ill-being aspects and thereby make things better for people (than very bad, say) without increasing functioning security. Consider the following policy-related example. By allowing homeless encampments to be established, harm can be reduced even if their inhabitants do not reach a threshold of goodness or secure functioning. In situations where people's valuable functionings cannot be attained, or made secure, harmful aspects can nevertheless be alleviated. By contrast, consider policies designed to rid cities of homeless encampments (Smith 2014: 36). If people are not afforded better options when homeless encampments are removed, then those policies negatively impact people's opportunities for avoiding negative beings and doings that arise from being pushed further into the margins of society and into isolation. Thus, people sometimes face different aspects of ill-being, some of which are prudentially worse than others.

Similarly, consider that homelessness often is an effect of structural causes like political-economical ones, and individual ones such as addiction and traumatic life histories (van Leeuwen 2018: 587). Regrettably, many homeless people die from substance (ab)use (Baggett et al. 2015; Beijer et al. 2011). Considering this, sobriety is easy to conceive of as a being that a person has reason to value. If people can be helped before they become addicted or supported when they risk relapsing, then their well-being will be made more secure. This is in line with Wolff and de-Shalit's focus on disadvantage. However, sobriety is sometimes not attainable for addicted people. When sobriety cannot be attained, we can nevertheless choose between well-being policies that make addicted people use drugs unhygienically on the streets, and policies that allow people to use drugs in sterile conditions under medical supervision. The second option is not promoting a being or doing that people have reason to value per se, but comparatively speaking it is in important ways less harmful than the first option is. We therefore ought to carefully consider states we do not have reason to value to adequately identify further relevant well-being aspects.

As a result, by identifying further well-being aspects, and ways of grounding them, capabilitarians can capture and assess a more complete range of relevant well-being aspects. The foundational modification I propose, to help capabilitarian well-being theories pass the ill-being test, can be resisted only at the cost of missing important ill-being information and related interventions.

By contrast with accounts that embrace the no-basic-bads view, the foundational modification to capabilitarian well-being theories that I propose better captures the differences between ways of not being well and ways of being unwell. For instance, it helps capture the basic badness of situations such as someone's being ignored, ostracised, demeaned, dominated, and sleeping rough. The modification also captures that differently negative beings and doings can underlie a shortfall of the same positive being or doing, but compound in ways that noting the mere deprivation does not. Focusing more extensively on states of being and doing that we do not have reason to value, since we have reason to disvalue them, thus captures important aspects of ill-being better than the no-basic-bads view does. From a practical perspective, this focus on ill-being aspects allows us to identify and address further 
negative beings and doings that people face and sometimes cannot avoid. One important end is to allow people to attain positive beings and doings. This is the only end sought after by proponents of the no-basic-bads view. However, some actual opportunities to avoid negative beings and doings are, as I have argued, importantly different from opportunities to attain positive beings and doings. Consequently, we should also mitigate basic bads, especially when this is the best that we can do.

\section{Conclusions}

To live well, we need to attain positive things such as eating enough and being mobile. To not live badly, we need to avoid negative things such as sleeping rough and feeling anxious. In aiming for high well-being, we should not lose sight of the negative things in life.

I recommend that we should directly assess aspects of people's ill-being. To understand what ill-being is, compare a person who is happy with a person who is sad and explore similar instances. We can, for instance, compare adequately housed people with people having to sleep rough and again with people having to sleep rough on spiked pavement. Similarly, we can compare respected individuals with ignored and ostracised individuals and again with demeaned and dominated individuals. These are different ways of not attaining comfortable sleep, and not attaining acceptable social standing. We should pay attention to the differences between such failures of attainment to identify what has gone wrong and what should be improved.

In conclusion, we should not only focus on deprivations to assess how badly off people are. We should also pay attention to people's actual opportunities to avoid enduring negative beings and doings. Only then can we do enough good for people in a good enough way.

Acknowledgements For constructive comments, I am grateful to participants at the Workshop on the Philosophy of the Capability Approach at the Ethics Institute of Utrecht University, the Research Seminar in Philosophy at Umeå University, the 2020 Human Development and Capability Association Conference, the Theories of Justice and Vulnerable Groups Workshop, and the Research Seminar in Human Rights Studies at Lund University. I also extend my gratitude to Kalle Grill, Jan-Willem van der Rijt, and Ingrid Robeyns for their valuable feedback. Furthermore, I wish to give my sincere thanks to the editor and two anonymous reviewers for this journal. I, however, take full responsibility for any potential demerits present in this paper.

Funding Open access funding provided by Umeå University.

Open Access This article is licensed under a Creative Commons Attribution 4.0 International License, which permits use, sharing, adaptation, distribution and reproduction in any medium or format, as long as you give appropriate credit to the original author(s) and the source, provide a link to the Creative Commons licence, and indicate if changes were made. The images or other third party material in this article are included in the article's Creative Commons licence, unless indicated otherwise in a credit line to the material. If material is not included in the article's Creative Commons licence and your intended use is not permitted by statutory regulation or exceeds the permitted use, you will need to obtain permission directly from the copyright holder. To view a copy of this licence, visit http://creativecommons.org/licenses/by/4.0/.

\section{References}

Alexandrova A (2012) Well-being as an object of science. Philos Sci 79:678-689. https://doi. org/10.1086/667870 
Alexandrova A (2017) A philosophy for the science of well-being. Oxford University Press, New York

American Psychiatric Association (ed) (2013) Diagnostic and statistical manual of mental disorders: DSM-5, 5 th edn. American Psychiatric Association, Washington, D.C

Angner E (2010) Subjective well-being. J Socio-Econ 39:361-368. https://doi.org/10.1016/j. socec.2009.12.001

Baggett TP, Chang Y, Singer DE, Porneala BC, Gaeta JM, O’Connell JJ, Rigotti NA (2015) Tobacco-, alcohol-, and drug-attributable deaths and their contribution to mortality disparities in a cohort of homeless adults in Boston. Am J Public Health 105:1189-1197. https://doi.org/10.2105/AJPH.2014.302248

Batterham D (2019) Homelessness as capability deprivation: a conceptual model. Housing Theory Society 36(3):274-297. https://doi.org/10.1080/14036096.2018.1481142

Beade GA (2019) Who can blame whom? Moral standing to blame and punish deprived citizens. Crim Law Philos 13:271-281. https://doi.org/10.1007/s11572-018-9471-z

Beijer U, Andreasson S, Ågren G, Fugelstad A (2011) Mortality and causes of death among homeless women and men in Stockholm. Scand J Public Health 39:121-127. https://doi.org/10.1177/1403494810393554

Bradford G (2021) Perfectionist bads. Philos Q 71(2):586-604. https://doi.org/10.1093/pq/pqaa055

Byskov MF (2020) Beyond "having reason to value": why we should adopt a procedure-independent and value-neutral definition of capabilities. J Econ Methodol 27:18-35. https://doi.org/10.1080/13501 78X.2019.1608584

Chang R (1997) Introduction. In: Chang R (ed) Incommensurability, incomparability, and practical reason. Harvard University Press, Cambridge, p 1-34

Crocker DA (2008) Ethics of global development: agency, capability, and deliberative democracy. Cambridge University Press, Cambridge

de Fine Licht KP (2017) Hostile urban architecture: a critical discussion of the seemingly offensive art of keeping people away. Etikk i praksis. Nord J Appl Ethics 11(2):27-44. https://doi.org/10.5324/eip. v11i2.2052

Durbin A, Nisenbaum R, Kopp B, O’Campo P, Hwang SW, Stergiopoulos V (2019) Are resilience and perceived stress related to social support and housing stability among homeless adults with mental illness? Health Soc Care Community 27(4):1053-1062. https://doi.org/10.1111/hsc.12722

Griffin J (1986) Well-being: its meaning, measurement and moral importance. Clarendon Press, Oxford

Heathwood C (2020) Happiness and desire satisfaction. Noûs. https://doi.org/10.1111/nous.12347

Heslin KC, Robinson PL, Baker RS, Gelberg L (2007) Community characteristics and violence against homeless women in Los Angeles County. J Health Care Poor Underserved 18(1):203-218. https://doi. org/10.1353/hpu.2007.0011

Hurka T (1993) Perfectionism. Oxford University Press, New York

Johnstone M, Jetten J, Dingle GA, Parsell C, Walter ZC (2015) Discrimination and well-being amongst the homeless: the role of multiple group membership. Front Psychol 6(739):1-9. https://doi.org/10.3389/ fpsyg.2015.00739

Kagan S (2014) An introduction to ill-being. In: Timmons M (ed) Oxford studies in normative ethics, vol 4. Oxford University Press, Oxford, p 261-288

Kahneman D, Krueger AB (2006) Developments in the measurement of subjective well-being. J Econ Perspect 20:3-24. https://doi.org/10.1257/089533006776526030

Khader SJ, Kosko SJ (2019) "Reason to value": process, opportunity, and perfectionism in the capability approach. In: Keleher L, Kosko SJ (eds) Agency and democracy in development ethics. Cambridge University Press, Cambridge, p 178-204

Kohn M (2004) Brave new neighborhoods: the privatization of public space. Routledge, New York

Noddings N (2002) Caring, social policy, and homelessness. Theoret Med 23:441-454

Nussbaum MC (2000) Women and human development: the capabilities approach. Cambridge University Press, Cambridge

Nussbaum MC (2003) Capabilities as fundamental entitlements: Sen and social justice. Fem Econ 9:33-59. https://doi.org/10.1080/1354570022000077926

Nussbaum MC (2011a) Creating capabilities: the human development approach. The Belknap Press of Harvard University Press, Cambridge

Nussbaum MC (2011b) Capabilities, entitlements, rights: supplementation and critique. J Hum Dev Capab 12:23-37. https://doi.org/10.1080/19452829.2011.541731

OPHI and UNDP (2020) Charting pathways out of multidimensional poverty: achieving the SDGs. United Nations Development Programme and Oxford Poverty and Human Development Initiative, New York and Oxford

Parfit D (1984) Reasons and persons. Clarendon Press, Oxford

Rice CM (2019) Objective list theories and ill-being. Ethical Theory Moral Pract 22:1073-1085. https://doi. org/10.1007/s10677-019-10035-5 
Robeyns I (2017) Wellbeing, freedom and social justice: the capability approach re-examined. Open Book Publishers, Cambridge

Sen A (1980) Equality of what? The Tanner Lectures on Human Values 1:195-220

Sen A (1985) Well-being, agency, and freedom: the Dewey Lectures 1984. J Philos 82(4):169-221

Sen A (1987a) On ethics and economics. Reprinted 1990. Blackwell, Oxford

Sen A (1987b) Commodities and capabilities. Oxford University Press, New Delhi

Sen A (1992) Inequality reexamined. Reprinted 2006. Oxford University Press, Oxford

Sen A (1993) Capability and well-being. In: Nussbaum MC, Sen A (eds) The quality of life. Oxford University Press, Oxford, p 30-53

Sen A (1999) Development as freedom. Knopf, New York

Sen A (2004a) Capabilities, lists, and public reason: continuing the conversation. Fem Econ 10:77-80

Sen A (2004b) Development as capability expansion. In: Sakiko F-P, Shiva Kumar AK (eds) Readings in human development: concepts, measures and policies for a development paradigm. Oxford University Press, New York

Sen A (2005) Human rights and capabilities. J Hum Dev 6:151-166. https://doi. org/10.1080/14649880500120491

Sen A (2009) The idea of justice. The Belknap Press of Harvard University Press, Cambridge

Smith AF (2014) In defense of homelessness. J Value Inq 48:33-51. https://doi.org/10.1007/ s10790-013-9405-x

Sumner W (1996) Welfare, happiness, and ethics. Oxford University Press, Oxford

Sumner W (2020) The worst things in life. Grazer Philos Stud 97:419-432. https://doi. org/10.1163/18756735-000108

UNDP (2010) Human development report 2010: the real wealth of nations - pathways to human development. United Nations Development Programme, New York

UNDP (2018) Human development indices and indicators: 2018 statistical update. United Nations Development Programme, New York

Vallentyne P (2006) Capability versus opportunity for well-being. In: Kaufman A (ed) Capabilities equality: basic issues and problems. Routledge, New York, p 79-92

van Leeuwen B (2018) To the edge of the urban landscape: homelessness and the politics of care. Polit Theory 46:586-610. https://doi.org/10.1177/0090591716682290

van Zalk N, Smith R (2019) Internalizing profiles of homeless adults: investigating links between perceived ostracism and need-threat. Front Psychol 10(350):1-12. https://doi.org/10.3389/fpsyg.2019.00350

Wall S, Sobel D (2020) A robust hybrid theory of well-being. Philos Stud. https://doi.org/10.1007/ s11098-020-01586-W

Wolff J (2009) Disadvantage, risk and the social determinants of health. Public Health Ethics 2(3):214-223. https://doi.org/10.1093/phe/php033

Wolff J, de-Shalit A (2007) Disadvantage. Oxford University Press, Oxford

Wolff J, de-Shalit A (2013) On fertile functionings: a response to Martha Nussbaum. J Hum Dev Capab 14(1):161-165. https://doi.org/10.1080/19452829.2013.762177

Yelle B (2014) Alienation, deprivation, and the well-being of persons. Utilitas 26:367-384

Publisher's Note Springer Nature remains neutral with regard to jurisdictional claims in published maps and institutional affiliations. 